http://dx.doi.org/10.12795/PH.1990.v05.i01.08

\title{
Sobre la reproducción del discurso
}

Manuel Bruña Cuevas

Este artículo se propone poner a descubierto lo que, a nuestro juicio, son análisis equivocados de las técnicas de reproducción del discurso, o sea, de las técnicas del discurso referido (DR), básicamente, estilo directo (ED), estilo indirecto (EI) y estilo indirecto libre (EIL). Analizaremos para ello algunas de las tipologías del DR propuestas en las dos últimas décadas.

Entre las tipologías más conocidàs y aceptadas se encuentra la de Brian McHale, 1978, asumida después por Gérard Genette, 1983. Dado que exponemos en detalle nuestra opinión al respecto en otro artículo ${ }^{1}$, nos limitaremos a resumir aquí nuestra principal crítica a esta tipología.

McHale declara (p. 261) que se propone sustituir «the discrete syntactical types of represented / reported discourse by a continuum based on literary categories of mimesis and diegesis». Ello nos parece perfectamente legítimo y factible, pero no creemos que el autor alcance su meta.

McHale parte del presupuesto de que el ED es más mimético que el EIL y éste más que el EI, cualesquiera sean las variantes de cada uno de estos procedimientos. Y sin embargo, si tales apelaciones tienen un sentido, es comprendiéndolas como técnicas diferentes desde el punto de vista sintáctico-enunciativo, pero neutras en cuanto a su capacidad mimética con respecto al discurso original, real o supuesto. Ninguno de los tres procedimientos es, por definición, ni más ni menos mimético que los otros; todo depende de cómo se empleen.

G. Genette, 1983, p. 38, da buena prueba de ello cuando, comentando la tipología de McHale, pone un ejemplo para cada una de sus categorías. Veámoslo.

1 «Sobre la mimesis del discurso» (en prensa), Primer Seminario de Narrativa, julio 1989, Cádiz. También analizamos aquí las posiciones de Graciela Reyes, Polifonía Textual, 1984, de las que no nos ocuparemos, por tanto, en el presente artículo. 
McHale define así sus categorías cuarta y quinta:

iv) Indirect discourse mimetic to some degree: this type of ID gives the illusion of «preserving» or «reproducing» aspects of the style of an utterance, above and beyond the mere report of its content. (p. 259).

v) Free indirect discourse: not only grammatically intermediate between ID and DD, but also mimetically intermediate (...), FID may, in fact, be mimetic to almost any degree short of «pure» mimesis.

Los ejemplos con que Genette las ilustra son:

iv) Marcel déclara à sa mère qu'il voulait épouser cette petite garce d'Albertine.

v) Marcel alla se confier à sa mère: il fallait absolument qu'il épousât Albertine.

Si la mímesis se define por «un maximun d'information et un minimun d'informateur» (Genette, 1972, p. 187), y si se parte ${ }^{2}$ del supuesto original «ll faut absolument que j'épouse cette petite garce d'Albertine», el ejemplo v presenta una cantidad de informador levemente inferior a la contenida en el ejemplo iv, pero una cantidad de información claramente por debajo. E incluso si se aceptara que hay neutralización de la proporción informador-información de un ejemplo a otro, el equilibrio quedaría definitivamente roto si el mismo «original» fuera referido con el EIL «Marcel alla se confier à sa mère: il voulait, dit-il, épouser Albertine». Este nuevo ejemplo sería menos mimético -a pesar de estar en EIL- que el ejemplo iv, que está en EI. Esto, sin embargo, no tiene cabida en la tipología de McHale, en la cual cada categoría representa un estadio más mimético que la anterior; según dicha tipología, nuestro último ejemplo habría que incluirlo en la categoría v («free indirect discourse») y sería, por tanto, más mimético que «Marcel déclara à sa mère qu'il voulait épouser cette petite garce d'Albertine», el cual, por ser un «indirect discourse mimetic to some degree», sólo es catalogable en la categoría iv; lo que constituye, a nuestro parecer, la evidencia de que McHale no alcanza su objetivo de constituir una tipología basada en criterios miméticos; y ello, por no desprenderse de la idea de que los tipos sintácticos tradicionales del DR representan, por definición, grados preestablecidos de capacidad mimética.

${ }^{2}$ Genette ha podido partir también del «original» «Il faut absolument que j'épouse Albertine», ya que es ésta la forma que le hace adoptar a la reproducción en ED y EDL (estilo directo libre), que representan las categorías sexta y séptima, más miméticas, según Genette y McHale, que las categorías anteriores. Pero este original no puede ser el que se reproduzca en iv, «Marcel déclara à sa mère qu'il voulait épouser cette petite garce d'Albertine», ya que entonces este último DR sería una ilustración de la categoría iii de McHale, pero no de la iv, en la que los DR reproducen los rasgos estilísticos del discurso «original». «Marcel déclara à sa mère qu'il voulait épouser cette petite garce d'Albertine» sería (si se supone que «Marcel dit à sa mère: Il faut absolument que j'épouse Albertine» es una reproducción literal del supuesto original) un EI en que no se reproduce el discurso «original» con sus rasgos estilísticos, sino con las palabras del locutor reproductor, es decir, repetimos, un EI de la categoría iii. Otra posibilidad es considerar la cualidad «mimético», no como «más o menos literal», sino como «más o menos conservador del sistema deíctico original»; pero, en ese caso, el concepto de «mimético» nos parecería perder todo su sentido desde el punto de vista literario. Sea como sea, y cara a nuestra argumentación, nada impide partir de un supuesto original «Il faut absolument que j'épouse cette petite garce d'Albertine», sin relación alguna, entonces, con la obra de Proust. 
Un razonamiento similar cabe hacer en lo referente al ED: un ED perifrástico será menos (o como mínimo igual, pero no más) mimético que un EI o un EIL fieles al contenido del discurso original, real o supuesto.

Jacqueline Authier, 1987, llama «pseudo-textuel» al ED perifrástico, es decir, al ED no literal: «Le pseudo-textuel explicite le fait que la citation qui rend compte des mots de 1 [el locutor del discurso original] est, paradoxalement, une traduction de ces mots dans les mots de L [el locutor que refiere el discurso original]» (p. 75). La autora no habla aquí del ED literario, sino del ED en general, y admite ella misma que los ED «seudotextuales» son «très fréquents» (p. 75). Tan frecuentes, creemos nosotros, que son los que establecen la regla en la lengua hablada corriente, aunque sólo sea porque la memoria humana no es comparable a los medios técnicos de grabación. La paradoja de que habla Authier, su «paradoxalement», no es sino el fruto del a priori de que partían McHale y Genette (que también recurre al término «paradoxe» para calificar estos mismo ED no literales; cf. Figures III, p. 192, nota 1): que el principal rasgo definidor del ED es la literalidad, su fidelidad al discurso original.

Authier comienza su artículo con una declaración de intenciones; se propone probar: a) que es erróneo considerar el ED como «la forme première, simple, du DR» de la que derivaría, a través del juego de la subordinación sintáctica, el EI, supuesta forma más compleja; b) que «il existe deux manières différentes de rapporter les paroles d'autrui; l'une d'elles, le DD [estilo directo] reproduit les mots eux-mêmes, par opposition à l'autre, le DI [estilo indirecto], qui n'est pas astreint à cette "fidélité"». Siendo incompatibles estas dos concepciones (a y b) del discurso referido, Authier dedica la primera parte de su artículo a analizar un cierto número de trabajos ${ }^{3}$ «selon qu'ils sont traversés, de diverses façons, par cette contradiction ou qu'ils y échappent» (p. 6), y la segunda a justificar el punto b); sus argumentos en pro de este segundo objetivo no nos han convencido.

Authier matiza la oposición tajante $\mathrm{ED}=$ repetición de las palabras del discurso original / EI=uso de tales palabras (p. 72), en el mismo sentido en que lo hará Genette en Nouveau discours du récit: a lo que se compromete un locutor que refiere un discurso en ED «c'est à répéter un message, en tant qu'il est une chaîne significative, et non pas à imiter celui-ci dans sa singularité physique de chaîne sonore» (Authier, p. 50). Se reafirma igualmente en la distinción que había hecho en un artículo anterior (1977, p. 75; firmado conjuntamente con André Meunier) entre «textualité» y «fidélité» del ED: «L'intégrité du signifiant de l'énoncé rapporté ne garantit pas la «transparence» du DD comme mode de rapport (au sens où à travers lui on retrouverait intacte la «vérité» de la parole initiale), elle tend le piège de cette fiction» (1978, p. 51). Todas estas puntualizaciones nos parecen harto acertadas ${ }^{4}$. No se comprende, en cambio, que, habiendo

${ }^{3}$ Los puntos de vista analizados son los de Jespersen, Wunderlich y las gramáticas escolares francesas, «marqués par une contradiction non résolue»; también aquellos otros que parten de una relación sintáctica ED-EI y los de Jacobs y Rosenbaum, Postal, Kuno y Ross, todos ellos condenados por tratar el DR desde un punto de vista puramente morfosintáctico; finalmente los trabajos elaborados en el marco de la gramática transformacional que han dado argumentos para disociar radicalmente ED y EI, sobre todo los de Sadock, Kuno y Banfield.

${ }^{4}$ Ver también A. Grésillon, 1978, y M. Stemberg, 1982, sobre estos mismos aspectos del tema. 
reconocido el fenómeno de los «îlots textuels» (empleo en un EI de ciertas palabras o giros del discurso original), no hable del fenómeno simétrico, de los «étangs textuels» (cf M. Plénat, 1979, p. 103; J. -C. Milner, 1978) o «îlots d'abstraction» (G. Strauch, 1984, p. 162) del ED (empleo en un ED de una palabra o un giro que sólo puede atribuirse al locutor que refiere el ED y no al locutor del discurso original):

Me he encontrado a Juan, que me ha dicho: «Ayer vi a Carmen con Fulano»; así que yo sé quién es su nuevo novio, pero no os lo diré.

Está claro que Authier no podía tener en cuenta este fenómeno, que arruina uno de los pilares de su concepción del ED: si bien es posible manipular un discurso referido en ED falseando su contenido por inserción en un contexto adecuado, «en tant que suite d'unités significatives, le message rapporté au DD ne subit (...) aucune altération, interprétation de la part de L [el locutor que refiere]. Les paroles de 1 [el locutor del dicurso original], laissées ainsi dans leur intégrité, sont isolées àj'intérieur du message de L, nettement delimitées par la rupture du dit: «...». Avant cette barrière, L parle; après, il ne fait que répéter: il s'efface à l'entrée des guillemets». Los «îlots d'abstraction» prueban que el locutor que refiere, el locutor reproductor del ED, no tiene por qué esfumarse después de las comillas, y yo mismo, en calidad de locutor, no lo hecho en mi última cita de las palabras de Authier: he introducido en su discurso un (....), rompiendo así la integridad de sus palabras, y he subrayado el texto (lo que equivaldría a una entonción significativa en lengua oral) después de haber traspasado la «barrera» de las comillas (sin hablar de que he preferido no introducir ningún «sịc»).

No sólo el locutor de un ED no tiene por qué desaparecer, sino que eualquier DR puede ser polifónico. «Dans les limites d'une seule et même construction linguistique, on entend les accents de deux voix différentes», escribe Bajtin, 1977, lo cual es aplicable a las construcciones del $\mathrm{DR}^{5}$ y se opone a la visión restrictiva de Authier; el ED no es la propiedad exclusiva de la voz del locutor del discurso original como el EI y el EIL no lo son de la voz del locutor que refiere. Los ejemplos aducidos por McHale, 1978, pp. 254-5, para rebatir las concepciones de Banfield, 1973, pp. 6-8, sobre el EI son buena prueba de la polivocalidad de éste. En lo que respecta al EIL, la visión de Authier requiere algunos comentarios.

Authier sólo dedica al tema unas cuantas páginas de su artículo, ya que ni siquiera lo considera como un tipo de $\mathrm{DR}$, sino como «une configuration discursive particulière» que le permite a un Loc (sujeto que habla; por oposición a L, locutor reproductor de un DR) hablar «avec les mots d'un autre». La autora se revela así como defensor moderno de la literalidad del EIL, en la misma línea de los pioneros del estudio de este tipo de DR, C. Bally y M. Lips; y sin embargo abundan los EIL construidos enteramente con las palabras del locutor que refiere; e igualmente los EIL que constituyen un resumen del discurso que se refiere; ¿habría que hablar en estos casos de «seudo-EIL»?

${ }^{5}$ Es muy frecuente reducir la polivocalidad del DR al EIL. Para O. Ducrot, por ell contrario, todo DR deja oír la voz del «locutor» y la del (o de los) «enunciador(es)», que asume(n) los actos ilocucionarios; si el locutor y el enunciador no coinciden, el DR, sea cual sea su tipo, es polifónico. 
Pero, de hecho, no es sólo por estos puntos por lo que su concepción del EIL no nos resulta apropiada. El concepto mismo de «connotation autonymique» del que parte para dar su definición del EIL nos parece inadecuado. Authier lo toma de J. Rey-Debove, 1971, para quien la «connotation autonymique» es el resultado de «un télescopage de l'emploi ordinaire des signes et de leur emploi autonymique, par lequel l'encodeur emploie pour parler du monde (et non des signes) une séquence rapportée, de telle sorte qu'il emploie et qu'il cite à la fois» (pp. 91-92). Como dice M. Plénat, el gran inconveniente de este concepto aplicado al EIL es el ser «impuissant à rendre compte de l'intervention d'autrui dans le discous d'un locuteur» (1979, p. 110).-

Señalemos también que la pragmática ha descubierto, en los límites de una sola y misma construcción linguística, perspectivas polifónicas insospechadas anteriormente.

Hasta aquí hemos tratado de los puntos de vista de Authier limitándonos al aspecto semántico. Pero, en realidad, su tipología tienen una base semántico-sintáctica, y si nuestro desacuerdo es grande en lo que respecta al primer componente, lo mismo ocurre en lo tocante a sus criterios sintácticos.

ED y EI, gracias a los verbos introductores «qui, explicitement, assertent l'existence d'un autre acte d'énonciation», serían, según Authier, «des formes définies grammaticalement, au niveau de la phrase, comme des DR (cf. dit: «...»/ dit que)» (1978, p. 79).

El EIL, en cambio, sólo es para ella, como ya hemos dicho, una configuración discursiva particular; no está «grammaticalement introduit par une marque» (ibid.) como lo están ED y EIL: «il est possible d'entreprendre l'inventaire lexical des verbes introducteurs de DD et de DI [estilos directo e indirecto]», mientras que «pour le DIL, le problème n'est pas de réunir les deux ensembles et d'ajouter, même, de nouveaux éléments: cet inventaire ne peut se faire» (ibid). Que se puede establecer una lista de verbos aptos para introducir el ED y el EI nos parece, en efecto, indiscutible; que no se agotará por ello la totalidad de los introductores posibles de ED y de EI nos parece igualmente evidente. Nada es tan cierto como decir que

les éléments qui sont susceptibles d'être repérés comme introduisant le rapport d'un acte de parole au DIL, sont des fragments de discours (évoquant d'une façon ou d'une autre, un acte de communication, ou seulement une personne, locuteur potentiel...) que l'on ne peut pas dénombrer. (Ibid).

Nada puede rebatir tampoco que esta afirmación es igualmente válida en el caso de los otros dos tipos de DR:

J'appuyais le nez à la vitre, et il fallait que ma bonne me tirât par le bras: «Monsieur Sylvestre, il est tard, votre maman vous grondera» (A. France, Le crime de Sylvestre Bonnard; citado por D. Bally, 1914, p. 413; citado también por Plénat, 1979, pp. 99100 con el mismo fin que lo está aquí). 
Sa pensée tâtonna un instant dans l'obscurité, il retira ses lunettes, en essuya les verres, se passa la main sur les yeux, et ne revit la lumière que quand il se retrouva en présence d'une idée toute différente, à savoir qu'il faudrait tâcher d'envoyer le mois prochain six ou sept mille francs à Odette au lieu de cinq, à cause de la surprise et de la joie que cela lui causerait. (Cité par D. Cohn, 1981, p. 57).

Si para poder hablar de ED y EI hiciera falta un aserción explícita de discurso -tal como Authier la entiende-es evidente que los casos anteriores serían algo distinto; ¿qué? la respuesta debería darla Authier, pero está claro que responder sería mucho más difícil en los casos en que falta todo elemento introductor -y una simple coma separa la narración del DR- o en aquéllos en que una misma estructura sintáctica comporta narración y DR:

Elle avait fermé les yeux, et des disques bleus se mirent à tourner, comme à la foire, hier, je tirais sur les disques avec des flèches de caoutchouc.

(Sartre, Le Mur; citado por D. Cohn, 1981, p. 82).

Elle ne prit même pas la peine de se peigner, tant elle était pressée, et les gens qui me verront ne sauront pas que je suis nue sous mon grand manteau gris. (Id.; Ibid., p. 82).

Como dice D. Cohn, «la continuité syntaxique n'empêche pas que le monologue soit nettement désigné comme tel par le changement de temps grammatical et de personne» (1981, p. 82). He aquí dos EI no explicitados según querría Authier:

...Et ne les [los alquimistas] saurait-on mieux comparer qu'à une bonne femme qui portait une potée de lait au marché, faisant son compte ainsi: qu'elle la vendrait deux liards; de ces deux liards.... (Citado por M. Lips, p. 127).

Là-dessus, les trois femmes de se précipiter sur moi comme si elles voulaient m'arracher les yeux. Que j'étais une brute, un sauvege, un assassin, et que c'était ma faute. (Citado por Verschoor, p. 18).

Digamos, para terminar nuestro análisis de la tipología de Authier, que cualquier teoría que recurra a un continuum, sin fronteras estrictas ni entre discurso primario y DR ni entre los diversos tipos de $\mathrm{DR}$, nos parece preferible a posiciones que defiendan que el ED y el EI tienen marcas específicas que los distinguen del discurso primario incluso fuera de contexto:

Il est possible de définir, par des propriétés internes à une phrase, ce qui fait qu'elle constitue un DD ou un DI, parce qu'elle contient des marques univoques, lexicales et syntaxiques: le DIL, lui, n'est pas une forme grammaticale. Rien ne permet, hors contexte, de dire qu'une phrase est du DIL. (Authier, 1987, p. 80).

Lo inexacto de esta afirmación salta a la vista; sáquese, por ejemplo, de su contexto el ED del ejemplo de A. France citado más arriba y nada lo diferenciará de un discurso primario. Y también puede ocurrir que, sin sacarlos de contexto, se deba considerar un 
ED o un EI como ambiguos. J. Simonin escribe en relación con Berlin Alexanderplatz:

Il reste que l'absence de contexte introducteur explicite de DD laisse parfois planer une certaine ambiguité sur le statut énonciatif de certains énoncés: s'agit-il de discours (de l'énonciateur) ou de DD libre? (1984, p. 35).

Buen número de discusiones sobre la ambigüedad del EIL serían evitables si se aceptara que un sólo enunciado puede dejar oír varias voces; si, ante un texto, no se hiciera la petición de principio de elegir entre la voz del narrador o la de un personaje; si se aceptara que ambas pueden manifestarse simultáneamente en una misma estructura sintáctica. Dado que con frecuencia no se parte de estos presupuestos, habría que recordar, al menos, a) que el EIL, como acabamos de decir, no es el único tipo de DR polifónico, aunque esta cualidad se le atribuya muy a menudo en exclusiva; b) que igual que hay ED y EI explícitamente señalizados, hay también EIL claros que no se pueden confudir ni con otro tipo de DR ni con el enuciado primario.

Estamos de acuerdo con que ciertas variantes del EIL podrían calificarse ce «formes d'hétérogénéité montrée non marquée», según los términos de Authier, que podrían catalogarse entre las formas más «arriesgadas» de heterogeneidad mostrada. Pero no vemos donde estribaría el riesgo de no reconocimiento de las palabras ajenas cuando un EIL va acompañado de un verbum dicendi ya como introductor, ya en inciso:

Juan se levantó y habló en estos términos: no colaboraría en un asunto de esa índole.

Fue justo entonces cuando Juan se levantó: no colaboraría -dijo- en un asunto de esa indole.

Resumiendo: cuando se habla de ED, EI o EIL, ya sea en la lengua literaria o en la lengua corriente, estas apelaciones sólo tienen sentido entendiéndolas como esquemas sintáctico-enunciativos, estando su capacidad mimética en función del empleo que de ellos se haga en cada caso. Aceptado esto, no habría inconveniente en admitir que cada época, cada autor, quizá también cada grupo social o incluso cada individuo -sería cuestión de estudiarlo-, tiene tendencia a servirse de estos moldes asignándole a cada uno una cierta capacidad en la escala de la reproducción literal de los discursos; ningún inconveniente tampoco en admitir que el ED es y ha sido a menudo preferido a los otros con vistas a reproducir literalmente el contenido original, real o supuesto, de un discurso, y ello por ser el único que conserva intacto el conjunto de referencias enunciativas originales, lo que sin duda refuerza la impresión de literalidad. Si se sigue este razonamiento, no haría falta crear subtipos que escapan a la norma, crear «seudos» o hablar de paradoja cada vez que la realidad presenta casos que no casan con posiciones teóricas preestablecidas y demasiado restrictivas.

Aceptar que ningún tipo de DR está asociado por definición a un grado concreto de mímesis no significa evidentemente, ya lo hemos dicho, que no sea legítimo construir una tipología del DR basada exclusiva o principalmente en criterios miméticos. $\mathrm{F}^{\mathrm{t}}$ nuestra opinión, una de las premisas principales de esta clase de tipología debería se la de disponer de una nomenclatura que obviara toda posible identificación de sus 
categorías con los tipos tradicionales. Cada una de estas categorías -o al menos algunas de ellas- debería poder dar cabida a cualquier variante del ED, EI o EIL; es decir, una tipología de los grados de mímesis del DR debería desprenderse del axioma que asigna de antemano, por definición, una determinada capacidad mimética a cada uno de los tipos sintáctico-enunciativos tradicionales del DR. En Figures III, Genette da un primer paso en esta dirección utilizando una terminología nueva: «discours narrativisé», «discours transposé» y «discours rapporté». D. Cohn hace igual («psycho-narration», «reported monologue» y «narrated monologue»), y también P. Hernadi («mimesis», «diegesis» y «subtitutionary narration»). Pero casi todo se queda en la terminología; por detrás sigue estando presente la tridivisión tradicional. Hernadi, 1972, por ejemplo, después de dar una definición de la «substitutionary narration» «in quasi-Platonic terms», dice: «From the point of view of grammar, subtitutionary narration emerges as an elliptical form of indirect quotation» (p. 36), y añade que, si hay que poner de relieve la característica que distingue básicamente a «subtitutionary narration» del ED y del EI, «this separating characteristic is the lack of a verbum dicendi» (p. 36). Estas dos afirmaciones (aparte el hecho de no parecernos exactas: el EIL no puede derivarse del EI) muestran a las claras que su criterio de «dual perspective» (que define a la «subtitutionary narration») sigue siendo subsidiario de condicionamientos gramaticales, dado que sólo puede aparecer en la estrucutura sintáctico-enunciativa del EIL. Siendo así, no vemos el interés de cambiar una apelación ampliamente aceptada por un neologismo.

Uno de los estudios más interesantes del DR, por la originalidad del enfoque aplicado, es el de Bajtin-Voloshinov en Le marxisme et la philosophie du langage. Los tipos de ED y de EI son establecidos tomando como referencia la interacción dinámica entre discurso que refiere y discurso referido: «L'erreur fondamentale des chercheurs qui se sont déjà penchés sur les formes de transmission du discous d'autrui, est d'avoir systématiquement coupé celui-ci du contexte narratif», a pesar de que «l'objet véritable de la recherche doit être justement l'intéraction dynamique de ces deux dimensions, le discours à transmettre et celui qui sert à la transmission» (p. 166). Cuando la interacción con el discurso ajeno apunta a conservarle la integridad y la autenticidad, aparecen esquemas lingüísticos que tienen por función protegerlo de infiltraciones procedentes de las entonaciones propias del autor; «les frontières qui séparent le discours rapporté du reste de l'énonciation sont tranchées et infranchissables»; se trata del «estilo lineal» de transmisión del discurso ajeno. Cuando ocurre lo contrario, cuando el contexto transmisor «s'efforce de défaire la structure compacte et close du discours rapporté, de le résorber, d'effacer ses frontières", aparece le "style pittoresque"». Según las épocas históricas (que determinan las condiciones de la comunicación socio-verbal) se utilizará preferentemente uno u otro de estos estilos.

Todas estas observaciones están contenidas en el capítulo nueve del libro. En el diez, el autor se propone estudiar cuáles son las estructuras que vehiculan la expresión lingüística de las dos tendencias descritas. Bajtin hubiera podido, por ejemplo, estudiar primero qué formas del EI y del ED corresponden al estilo lineal y después las que corresponden al estilo pintoresco; pero no procede así. Víctima, en nuestra opinión, del p'eso de la tradición, que separa radicalmente ED y EI, y víctima igualmente de su 
propósito de asignar a cada periodo histórico determinadas formas de $1 \mathrm{DR}^{6}$, Bajtin analiza primero las variedades de EI, luego las de ED y finalmente el EIL, que: trata como un todo homogéneo.

En relación con el EI, Bajtin habla de tres variantes: el «discurso indireıto objetoanalítico», el «verbo-analítico» y el «impresionista». El primero «appréhenide l'énonciation d'autrui au plan puremente théorique (p. 179) y conserva «une distance nette et stricte entre les paroles du narrateur et les paroles rapportées», lo que hac'e de esta variante «un instrument parfait de transmission du discc)urs d'autrui en style linéaire» (p. 180). El segundo «intègre à la construction indirecte les mots et les tournures du disicours d'autrui qui caractérisent la configuaration subjective et stylistiqu ue de ce dernier en tant qu'expression» (p. 181). Dichos giros y pala!bras «prennent du reilief, leur "ccloration" ressort plus clairement, et en même temps s'y ajoutent les nuances propres à l'aauteur: ironie, humour, etc» (p. 182). En posición internedia entre las dos váriantes anteriores, el discurso indirecto impresionista trata «le discours d'autrui avec betsucoup de liberté», abreviándolo a menudo para no indicar sino «ses thèmes et ses dominauntes»; «l'intonation propre à l'auteur déborde facilement et lib.rement dans sa strndcture flex.ible» (p. 183). Estas dos últimas variantes son, según el autor, el instrumento del estilo pintoresco.

En lo relativo a las variantes del ED, hay una, el «estilo directo preparado», «où le diiscours narratif mène l'assaut contre l'énonciation rapportée» (p. 184); «de c 'ette façoin, les frontières de l'énonciation d'autrui sont très affaïblies»; en general, « 'ne infiltration aussi profonde de l'intonation de l'auteur dans le discours direct va toujoi urs de pair avec un affaiblissement de l'objectivité du contexte narratif lui-même» (p. 18: 5). El «discurso directo vaciado de su substancia» también responde a la tendencia anteric ir: «le crontexte narratif y est construit de telle façon que la caractérisation objective d 'u héros; par l'auteur jette des ombres épaisses sur son discours direct. Les appréciation $\mathrm{s}$ et la valeur émotionnelle dont est chargée sa représentation objective se transmetten t aux ] paroles du héros» (p. 185-6). Tras estas variantes «à double sens, á deux visages», Bajti in alude al «discurso directo retórico», una de las variantes «lineales» más impo stantes del ED: «mais nous ne pouvons pas nous y attarder. Nous he nous arrêterons qu'à quelques manifestations rhétoriques concomitantes» (p. 190j) que hacenposible el naci miento del EIL, según el autor.

Como se ve, Bajtin, consecuente con su teoría de 1'a polivocalidad, no cae en el erro r usual de considerar que no hay más que una voz er ${ }_{1}$ la reproducción directa; se trate

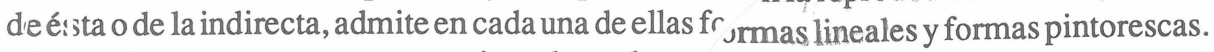
¿,Por: qué entonces no poner en primer lugar la p^ srspectiva de interrelación dinámica? ¿Por qué subordinarla ahora, en el capítulo di.ez, a un a perspectiva sintáctica? Bajtin reconnoce que cada forma de $\mathrm{DR}$ «recrée à sa r. nanière l'é nonciation, lui donnant ainsi une

${ }^{6}$ Einn general estamos de acuerdo con la visión de Batjin sobre ] la distribución histórica de las formas de: DR. Discrepamos sin embargo en lo concerniente a la época medie val. Batjin, apoyándose en las opinirones de G. Lerch y de C. Bally, mantiene que el EnL aparece por primerc 1 vez, salvo raras excepciones anteriores, en la literatura del siglo XIX. Esto es erróneo; el EIL es de uso cr orriente en la Edad Media; cf. M. Brruña Cuevas, 1988. 
orientation articulière, spécifique» (p. 176); pero parecería como si hubiera que entender ací esta afirmación, no como una constatación de que hay unas formas indirectas directas- que corresponden al estilo lineal y otras que corresponden al estilo pintoresco ino en el sentido de que la diferencia sintáctica directo-indirecto supone de entrada unorientación diferente, lo que parece estar en contradicción con sus posiciones anterics. ElEI, dice Batjin, posee una «signification linguistique»: «la transmission analytiqudu discours d'autrui. L'emploi du discours indirect ou de l'une de ses variantes.pplique une analyse de l'énonciation simultanée et inséparable de l'acte de transposi)n» (p. 177). «L'analyse est l'âme du discours indirect» (p. 178). Incluso admitien que esta propiedad sea inherente al EI, no vemos cómo se podría admitir que ese mișn análisis no se da, simultánea e inseparablemente, cuando la transmisión del discursojeno se hace en ED; cómo un ED puede ser «vaciado de su sustancia», cómo puede s «preparado», sin que haya análisis simultáneo; cómo un ED puede ser «à double ns, à deux visages», sin que se efectúe al mismo tiempo un análisis del discurso que seefiere. Creemos, en suma, como ya hemos dicho, que Batjin, tras tratar magistlmente de la naturaleza de la transmisión del discurso ajeno, se contradice a continición en sus propios términos por un deseo equivocado de asignar valores apriorística formas del DR establecidas según criterios sintácticos.

sto que decimos se hace aún más patente cuando trata del EIL. Polivocálico, comfiertas variantes de ED y EI, el autor le exige además que la doble voz que en él resua tenga dos «acentos» diferentes. Tras una cita de El prisionero del Cáucaso de Puslin, señala que la mayoría de los autores que han escrito sobre el EIL reconocerían en et un casoevidente de esta técnica: «cependant, pour notre part, nous sommes enclin à coidérer qu'il s'agit dans ce cas d'un discours par substitution. (...) Dans l'exemple quıous avons utilisé, il manque l'interférence entre le discours narratif et le discours raprté, et, par conséquent, les indices grammaticaux et syntaxiques qui créent cette inférence, qui caractérisent le discours indirect libre pour le distinguer du contexte natif environnant» (p. 193; subrayado nuestro). Cabe preguntarse por qué construir u teoría del DR tan original y atractiva para tirarla luego por la borda sacrificándola aondicionamiontos sintácticos.

Si no aprobamos 'sta sumisión a criterios sintácticos en el caso de la tipología de ajtin, no es porque no -oncedamos importancia a los rasgos gramaticales que aracterizan al ED, EI y EIL. o que rechazamos es la atribución a cada uno de estos

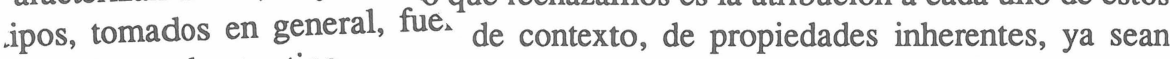
miméticas o de otro tipo.

G. Strauch, 1984, condena la tip e gía de McHale basada en la literalidad de los liscursos. Negando toda valideza la inta mretación sistemática del ED como «copie

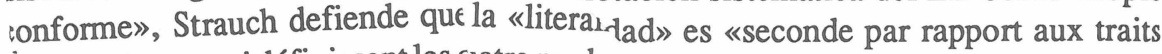
grammaticaux qui définissent les çatre modes $\mathrm{c}$ DR» (ED, EI, EIL y EDL). Ya hemos sugerido en los comentarios anteiores que no has por qué considerar la literalidad primaria ni secundaria por definicin; puede ser un rasgo primario en una tipología de los DR a condición de que no se coiundan las categorías que contenga con los tipos del trío ED-EI-EIL. 
Tras definir lo que entiende por «literalidad», Strauch construyein cuadro de los tipos de DR partiendo de los rasgos gramaticales «regido-no regido y «oblicuo-no oblicuo». Obtiene así cuatro tipos simétricos: discurso indirecto (DI: egido-oblicuo), discurso directo (DD: regido-no oblicuo), estilo indirecto libre (EIL: noregido-oblicuo) y estilo directo libre (EDL: no regido-no oblicuo). Aparte de la fuente e equívocos que puede ser el término «regido» aplicado al $\mathrm{ED}^{7}$, el cuadro de Strauch ıs parece dejar entrever «une symétrie un peu factice ou spécieuse entre les divers éats des discours direct et indirect» ${ }^{8}$. El sistema de referencias enunciativas de los dos ipos de ED (ED y EDL) será siempre el mismo que el del discurso original; desde estepunto de vista, no existe pues ninguna diferencia entre ED y EDL. Por el contrario, el omportamiento en este sentido del EI y del EIL, aunque a veces idéntico, no es forzosanente el mismo. Mientras que un sólo tipo de marcas enunciativas (las personales o las virbotemporales) establecidas en relación al contexto o a la situación de enunciacióndel locutor que refiere es suficiente para que haya EIL, el EI exige que todas estas marcis estén referidas a dicho contexto o a dicho locutor'.

Somos consciente de que esta descripción nuestra de la «oblicuilad»-para hablar como Strauch- del EIL no se adecúa a lo que comúnmente se repitedesde la primera definición dada por Tobler en el XIX: «mezcla particular de los dscursos directo e indirecto, que toma del primero la entonación y el orden de las palatras y del segundo los tiempos y las personas de los verbos».

En lo relativo a la similitud entre EI y EIL, pronto se comprobć que los adverbios temporales no respondían siempre a las mismas pautas en uno y otro estilo, pero el acuerdo en que era común el comportamiento de las marcas personales y verbotemporales ha permanecido como axioma inquebrantable a lo largo de este siglo. Y sin embargo:

A une certaine époque, on parla beaucoup de mariages dans la famille. La fillette choisit pour son futur mari un jeune homme de vingt ans qui s'occupait souvent d'elle. Un jour elle vint à moi toute triste: elle ne pourra pas épouser son ami; cela durera trop longtemps jusqu'à ce qu'elle ait l'âge de se marier; lui sera trop grand et trop vieux pour elle; il faut qu'elle choisisse un garçon de son âge. (Wettstein, Les notions de temps chez l' enfant. Citado por Lips, pp. 65-6).

Nótese que las marcas temporales de los verbos subrayados están establecidas en relación al presente de enunciación de la niña, no en relación al del locutor que refiere,

${ }^{7}$ Véase por ejemplo la crítica que Genette, 1983, p. 39, dirige a Strauch: El ED «n'est par définition jamais régi». Strauch se defiende en 1984, p. 177.

${ }^{8}$ Esta crítica corresponde a una salvedad que Genette hace a su aceptación de la tipología de MacHale; éste, como Strauch, hace la diferencia entre ED y EDL.

${ }^{9}$ En el EI, ciertas marcas pueden escapar a veces a esta referencia obligatoria a la situación enunciativa de locutor que refiere. Aun así, está claro que, para que un EI se constituya, es preciso establecer con respecto a la situación enunciativa del locutor que refiere o al contexto más de un tipo de marcas; las desinencias temporales de los verbos y las marcas personales, especialmente, están siempre referidos en francés o español modemos -no era así en francés medieval- a la situación enunciativa del locutor que refiere 0 al contexto, lo cual no es obligatorio en EIL. 
para quien los procesos expresados por estos verbos no están situados en el futuro, sino en el pasado. Este sistema de referencias enunciativas sería inviable en el EI. En la cita anterior, comprendida como el relato de una situación pasada -la niña ya no ve a su amigo de veinte años en el momento en que el locutor nos refiere sus palabras, por ejemplo-, si se hubiera elegido el EI para referimos la primera oración que está en EIL, hubiera habido que recurrir a una frase del tipo

Un jour elle vint à moi toute triste et me dit qu'elle ne pourrait pas épouser son ami.

donde el potencial pourrait indica un futuro en relación con el pasado establecido por el contexto, concretamente por elle vint. Este tipo de referenciación contextual constituye lo habitual en EI cuando la enunciación reproducida y el proceso significado por el verbo son pasados para el locutor reproductor. La misma construcción es igualmente posible, y hasta usual, en el EIL, pero no reviste el carácter prácticamente obligatorio que tiene en el EI: en nuestra cita, el condicional sería igualmente posible, pero no es obligatorio como en el caso de la versión en EI. De ahí el futuro pourra, referenciado al presente de enunciación del locutor original, es decir, al momento en que hablaba la niña, referenciación de todo punto inviable en la versión en $\mathrm{EI}^{10}$.

En lo concerniente a las marcas personales, las posibilidades del EIL no son tampoco -mal que le pese a la opinión común- las mismas que las del EI. En EI, todas estas marcas están siempre referenciadas al locutor que refiere o al contexto. El EIL permite, en cambio, que se mantenga un sistema deíctico personal referenciado al locutor del discuro original. He aquí un ejemplo sacado de C. Bally, 1914, p. 419, e incomprensiblemente ignorado posteriormente ${ }^{11}$ :

Pierre m'avait donné rendez-vous pour huit heures; mais empêché au dernier moment, je n'avais pu ni le rencontrer ni le prévenir. Pierre vint au devant de moi, attendit longtemps; il s'inquiétait: Lui serait-il arrivé quelque chose? Etait-il malade? Et personne de sa part!

\footnotetext{
${ }^{10}$ No ocurre igual cuando la enunciación referida no es pasada con respecto al presente del locutor que refiere, sino futura o presente, o cuando, siendo pasada, el proceso verbal no es pasado en relación con el presente de enunciación del locutor que refiere. Cuando la enunciación referida está situada en el futuro del locutor que refiere, los morfemas verbo-temporales de un EI pueden -aunque no es obligatorio - estar referenciados al presente de enunciación del locutor «referido», original; el carácter futuro de la enunciación está indicado entonces exclusivamente por el verbo introductor de EI; así en «Juan dirá [el 15] que te vio [el 14] en el cine» [y estamos a 13], el hecho de que la enunciación referida es futura está únicamente indicado por el introductor «dirá», mientras que «vio», tiempo gramatical pasado, está referenciado con respecto al presente de enunciación de Juan -para quien la acción de ver es pasada-, pero no con respecto al presente de enunciación del locutor que refiere las palabras de Juan, pues para él el proceso de «ver» constituye un futuro, lo cual no nos lo indica el pasado «vio».
}

${ }^{11}$ Para construir su ejemplo, Bally se inspira del texto literario siguiente:

Un soir, nous sommes attendus: Emile a reçu l'ordre. On vient au devant de nous; nous n'arrivons point.

Que sont-ils devenus? Que leur est-il arrivé? Personne de leur part! La soirée s'écoule à nous attendre. (J. - J. Rousseau, Emile). 
«Lui», «était-il», «sa part»se refieren todos al locutor reproductor de los pensamientos de Pierre y no han sufrido la transposición a la primera persona que hubiera sido obligatoria si el discurso de Pierre se nos hubiera transmitido en $\mathrm{EI}^{12}$.

Indudablemente, los casos en que sólo las marcas verbo-temporales y no las personales (caso de la cita anterior) están referenciadas al locutor que refiere son menos abundantes que aquellos en que ambos tipos de marcas lo están (lo cual es lo más corriente en español o francés modernos, menos en francés medieval) o incluso que aquéllos en que sólo lo están las personales (caso de la cita sacada de Wettstein; pág. 91). $\mathrm{Si}$, a pesar de ello, nos parece que hay que tener en cuenta los casos de la primera de estas tres posibilidades es por una cierta desconfianza hacia las generalizaciones basadas en datos estadísticos, las cuales llevan a menudo a conclusiones precipitadas que requieren después la elaboración de una lista de excepciones, de exclusiones y de casos marginales:

Il ne faut en effet pas se laisser séduire par les chiffres, dont le maniement fait parfois oublier ce qui différencie le code de l'utilisation du code. Si une structure apparaît ne serait-ce qu'une seule fois, elle a place, à part entière, dans le code dont elle relève. (B. Cerquiglini, 1981, p.30).

Recordemos, sin embargo, que, incluso si los EIL con las marcas personales no referenciadas al locutor que refiere no existieran, la diferencia entre EI y EIL desde el punto de vista enunciativo seguiría siendo importante. El EI no tiene la libertad del EIL de referenciar las marcas verbo-temporales en relación bien a la situación de enunciación del locutor del discurso original, bien al discurso o a la situación de enunciación del locutor que refiere: el EI sólo puede responder a esta segunda posibilidad.

La simetría establecida por el cuadro de Strauch -volvemos a ello- es por tanto engañosa. Los discursos directo y directo libre no presentan nunca entre sí ninguna diferencia desde el punto de vista enunciativo, mientras que esta identidad de comportamiento no es más que una posibilidad en la mitad «indirecta» de su cuadro. Pasemos ahora al rasgo «regido-no regido».

Strauch emplea el término «regido» para indicar que el ED y el EI vienen precedidos de un verbo declarativo. $\mathrm{Si}$ «regido» sólo quisiera decir esto, no tendríamos mucho que objetar (aparte de lo equívoco del término elegido, como ya hemos dicho); pero el autor parece atribuirle un sentido más amplio cuando defiende su término contra la crítica de Genette: el de «gramaticalmente subordinado» (1984, p. 177), con lo cual no podemos estar de acuerdo:

Car, au fond permanet de pommes de terre, de confiture, de biscuits, qu'elle ne nous annonçait même plus, Françoise ajoutait -selon les travaux des champs: une barbue,

12 Curiosamente, Bally no se da cuenta tampoco de esta diferencia entre EIL y EI en lo relativo a las marcas personales. Con este ejemplo, el autor trata de probar que la primera y segunda personas no pueden aparecer en EIL; no obstante, si en él se sustituye la tercera persona por la primera, sigue habiendo un EIL impecable, de un tipo, además, bastante frecuente en los relatos autobiográficos. 
«parce que la marchande m'en a garanti la fraîcheur», une dinde, «parce que j'en ai vu une belle au marché», un gigot rôti, «parce que le grand air creuse et qu'il a bien le temps de descendre d'ici sept heures», des cerises, «les premières qui viennent du cerisier du jardin après deux ans»...

Hay en este ejemplo varios ED sin verbo declarativo introductor pero, a pesar de todo, «grammaticalement subordonnés»; son pues, según la terminología de Strauch, regidos-no oblicuos, es decir que son estilos directos, no estilos directos libres, lo que no concuerda con las previsiones del cuadro de Strauch, según el cual todo DD, todo estilo directo, debe ir precedido de un verbo declarativo. Para nosotros no es chocante hablar de ED en el caso de los DR del ejemplo anterior, pero qué nombre dar, según los criterios de Strauch, a los DR siguientes:

Car, au fond permanent d'oeufs, de côtelettes, de pommes de terre, de confiture, de biscuits, qu'elle ne nous annonçait même plus, Françoise ajoutait -selon les travaux des champs: une barbue, parce que la marchande lui en avait garanti la fraîcheur, une dinde, parce qu' elle en avait vu une belle au marché de Roussainville-le Pin, ... un gigot rôti, parce que le grand air creuse et qu' il avait bien le temps de descendre d' ici sept heures, ... des framboises que M. Swann avait apportées exprès, ... un gâteau aux amandes parce qu' elle l'avait commandait la veille, une brioche parce que c'était notre tour de l'offrir. (M. Proust, Du côté de chez Swann; Lips, pp. 46-7).

Se trata aquí de formas oblicuas-regidas, es decir de formas que responden a los rasgos que caracterizan el EI. Suponemos que el propio Strauch estará de acuerdo con nosotros en que aquí se trata en realidad de EIL subordinados, no de EI. En estas condiciones, no vemos otra manera de salvar el cuadro sintáctico de Strauch que interpretando el rasgo «regido», no como «gramaticalmente subordinado», sino más bien como «gramaticalmente subordinado a un verbo transitivo cuyo complemento directo está representado por el DR»; con esta interpretación, los $\mathrm{DR}$ de los dos últimos ejemplos podrían considerarse como no regidos, y, por tanto, como EDL y EIL respectivamente, lo que sí nos parece ya natural. Claro está que, con esta restricción del alcance de «regido», la elección del término parece menos acertada de lo que ya era, sin contar con que, incluso así, el cuadro de Strauch no es apto para dar cuenta de todas las variantes del DR. Los EIL siguientes, por ejemplo, serían agramaticales según el cuadro de Strauch:

Un día vino a verme y me anunció: si su marido no cambiaba se divorciaría y cambiaría de ciudad.

Furioso ante tal afirmación, se levantó y declaró con voz de rabia: nunca fue él partidario de la censura, nunca dijo que...

Y es que Strauch parte del principio de que, cuando las formas no regidas (EDL y EIL) van precedidas de un verbo declarativo transitivo, éste debe estar «"saturé" par un objet grammatical autre que l'énoncé rapporté» (1984, pp. 177-8). Desde nuestro punto de vista, esta condición sólo es necesaria para la simetría de su cuadro y su concepción de 
la rección: el ED está regido porque funciona como complemento directo del verbo introductor, si éste está "saturado" por un complemento distinto al DR, hay que hablar de EDL. Sólo que en el campo de la reproducción oblicua, admitir que un EIL puede estar introducido por un verbo declarativo no saturado equivaldría a decir que está regido; y entonces, como el rasgo «no regido» es el único que lo diferencia del EI, no habría casilla oblicua donde incluir tal caso; de ahí su petición de que nuestros últimos ejemplos de EIL (anunciados por verbos transitivos no saturados) sean agramaticales.

No es de extrañar que, si no hay casilla para los EIL precedidos de verbos transitivos no saturados, tampoco la haya para los EI anunciados por verbos transitivos saturados: el EI tiene que ser obligatoriamente, según Strauch, el complemento directo de un verbo transitivo no saturado por otro objeto directo; los casos que proponemos en la página ochenta y seis para rebatir la argumentación de Authier desmienten también, en este punto, la posición de Strauch.

Creemos, en resumen, que el cuadro de Strauch no es bastante potente para dar cuenta de todas las posibilidades del DR; ni siquiera restringiendo el sentido de «regido». De todas formas, no creemos que tal restricción esté prevista por el cuadro. Seguramente Strauch, como la mayor parte de los investigadores del tema, ha interpretado la denominación «estilo indirecto libre» como sinónimo de «estilo indirecto no subordinado»; y sin embargo no es exactamente así como su creador, Charles Bally, parece haberla concebido.

La frase en que el término «estilo indirecto libre» aparece por primera vez deja entender que «libre» quería decir para Bally liberado de la conjunción de subordinación obligatoria en el EI francés y de la cual puede prescindir el EI alemán: «Le français connaît un style indirect libre non conjonctionnel analogue à celui de l'allemand» (1912, p.550). Para probarlo, pasa a citar una serie de ejemplos agrupados según el número de EI con que que preceden la aparición de un EIL: a) «L'énoncé est introduit par trois subordonnées; le reste se passe de conjonction».b) «Deux subordonnées seulement ouvrent le discours indirect, le reste a la forma libre».c) «Seule la première proposition reste subordonnée». Finalmente d) «Toute trace de subordination peut disparaître». Pero lo que Bally entiende aquí por «subordination» es de hecho la subordinación a un verbo credendi o dicendi. Es por ello por lo que dentro del grupo d) puede establecer un subgrupo en los términos siguientes (es el propio Bally quien subraya):

Les paroles ou les pensées reproduites peuvent enfin se trouver dans une simple proposition relative:

Les amis de Wallenstein s'abandonnèrent aux plaisirs de la table et portèrent des toasts exaltés au grand homme qui, disaient-ils, avait cessé d'être le jouet de la perfidie de l'empereur pour devenir un prince indépendant.

Que l'on supprime l'incidente disaient-ils et l'on aura le style indirect absolument libre... (p. 554). 
De hecho, sin que sea necesario suprimir ningún inciso, en la página 556 se lee el ejemplo siguiente: «Je me fis conduire vers le petit hôtel de la rue de Madrid, où je déposerais une carte».

Como se ve, «libre» sólo se oponía en parte, no radicalmente, a «subordonné» para el creador de la apelación «style indirect libre». Lamentamos, no obstante, la falta de seguridad de que da muestras Bally en este punto; ¿por qué decir que «les paroles ou les pensées reproduites peuvent enfin se trouver dans une simple proposition relative» en vez de «dans une simple proposition subordonnée, relative ou circonstancielle»? Seguramente se debió a que hasta entonces había hablado de «style indirect libre non conjonctionnel», lo que hacía parecer contradictoria la aceptación de EIL en forma de oraciones circunstanciales, normalmente introducidas por una conjunción. Si creemos que quiso simplemente evitar esta contradicción terminológica es porque, algunas páginas después, cita el siguiente caso como ejemplo de «style indirect libre ạvec incidente»:

Le curé s'émerveillait de ces dispositions, bien que la religion d'Emma, trouvait-il, pût, à force de ferveur, finir par friser l' hérésie et même l' extravagance. (G. Flaubert, Madame Bovary) (subrayado por Bally).

Hemos dicho que lamentamos la manera en que Bally trata el EIL subordinado ${ }^{13}$. En efecto, su vacilación traerá consecuencias negativas.

M. Lips, discípula suya, se expresará con los mismos términos imprecisos que Bally: «La syntaxe des propositions [en el EIL] est indépendante, pas de verbe introducteur transitif» (p. 51). Otra vez la independencia sintáctica atribuida al EIL se pone en relación con la exclusión para este tipo de DR de las completivas características del EI. Esta exclusión viene explícitamente afirmada: «Le style indirect libre ne peut fonctionner comme régime direct d'un verbe transitif, ce qui l'oppose á l'indirect ordinaire et au direct» (pp. 51-2). Pero, como Bally, Lips no tiene inconveniente en subrayar como EIL la relativa del ejemplo siguiente:

(...) Il fut grossier, excitant les autres contre le caporal, qui les laissait mourir de faim. Oui, c'était sa faute, si la escouade n' avait rien mangé... (E. Zola, La débâcle; Lips, p. 70).

No obstante, el libro de Lips representa un paso atrás en el reconocimiento del EIL subordinado. En ningún sitio se halla en Lips una declaración explícita sobre las relativas en EIL. La posición clara de Bally sobre este tipo de subordinada debió de animarla a considerar la relativa del ejemplo anterior como un caso de EIL, pero, ante las oraciones adverbiales en EIL, Lips retrocederá. Lips no sabe cómo interpretar los casos claros de EIL subordinados con los que topó en su repaso de la literatura francesa.

13 «Estilo indirecto libre subordinado» no parece una expresión afortunada. Quizá sea a fin de cuentas la elección de la apelación hecha por Bally -elección de la que él mismo sería la primera víctima- lo que haya que lamentar. 
Entre otros, los pasajes de Proust y de Flaubert que hemos citado anteriormente (pp. 94 y 96 respectivamente) o el siguiente:

J'avais, dans la rue de la Madeleine, un porteur d'eau auvergnat, appelé Christal, qui a nourri pendant cinq mois gratis un tapissier qui lui était inconnu et qui était venu à Paris pour un procès, «parce que», me disait-il, «ce tapissier, le long de la route, dans la voiture publique, avait donné de temps en temps le bras à sa femme malade». (Bernardin de Saint-Pierre, Etudes de la nature. Lips, pp. 48-9).

Estos casos los sitúa Lips al final del capítulo sobre el EI, limitándose a comentar: «Ici nous touchons à des faits qui nous amènet dans un tout autre domaine de la reproduction indirecte et auquel nos développements précédents devaient frayer la voie», es decir, al EIL, al cual está dedicado el capítulo que sigue a esta frase. La falta de claridad en el artículo de Bally lleva así directamente a la exclusión del campo del EIL de toda construcción sintácticamente subordinada.

El libro de Lips se convirtió rápidamente en una especie de manual de iniciación para los investigadores interesados en el EIL, quedando así el término «libre» identificado a «independiente desde el punto de vista gramatical».

Esta desviación del sentido hubiera podido evitarse si el siguiente trabajo general dedicado al EIL en francés -la tesis de J. A. Verschoor- hubiera sido más conocido. Por desgracia su director de tesis se equivocó: «A tous les points de vue sa thèse renouvelle et dépasse donc l'ouvrage de Lips, qui, jusqu'ici, nous servait de référence pour cette question» (L. Wagner, 1960). Al contrario de lo que Wagner afirma aquí, Lips servía y sigue sirviendo de referencia, mientras que a Verschoor ni siquiera se le cita en un gran número de trabajos ${ }^{14}$. Verschoor defiende la existencia del EIL gramaticalmente subordinado, pero hasta el punto de que lo ve donde no lo hay. Prácticamente toda completiva sin que colindante con un EI, o incluso toda causal, merece para él el estatus de EIL. A pesar de esto, una mayor difusión de su libro, aunque sólo fuera por los casos correctos que aporta, hubiera evitado el olvido de la variante subordinada del EIL.

En nuestra opinión, si es preciso delimitar los campos respectivos del ED, EI y EIL, hay que establecer una primera distinción de orden enunciativo entre ED, por un lado, y EI y EIL, por otro: el ED tendrá siempre todas las marcas enunciativas referidas a la situación de enunciación del locutor del discurso original, real o supuesto; en cambio, para que haya EI o EIL, es necesario que la condición anterior no se cumpla.

La distinción entre EI y EIL se realiza en un doble plano: el enunciativo y el sintáctico. Desde el punto de vista enunciativo, el EI siempre tendrá establecidas todas las marcas en relación con el contexto o con la situación de enunciación del locutor que refiere. El EIL, en cambio, sólo presenta como exigencia mínima que estén referenciadas con respecto al contexto o al locutor que refiere $o$ bien las marcas personales $o$ bien

${ }^{14}$ Verdín Díaz (1970, primer trabajo amplio dedicado al EIL en español), por ejemplo, no parece conocer la tesis de Verschoor, con lo cual, entre los numerosos tópicos que repite, se encuentra igualmente el de que este tipo de DR sólo aparece en oraciones independientes. 
las marcas verbo-temporales, aunque admita -e incluso sea el caso más frecuente en el empleo que de él se hace en la época moderna- un sistema de referencias idéntico al del EI. Aparte estas exigencias mínimas, el EIL presenta, como hemos señalado más arriba (pp. 91-93), posibilidades de referenciación que no son viables en EI.

Desde el punto de vista sintáctico, el EI siempre estará constituido por una completiva subordinada a un verbo (o locución) declarativo o que pueda interpretarse como tal, presente en el texto o sobreentendido. Este tipo de oración es precisamente la única que no vehicula nunca una reproducción en EIL.

Desde este mismo punto de vista sintáctico, no se puede establecer una distinción entre el ED y los otros dos modos aplicable a todas sus variantes respectivas. El ED está constituido las más de las veces por una construcción sintácticamente independiente, pero esto es igualmente lo más corriente en el caso del EIL; y si el ED puede aparecer en una subordinada relativa o circunstancial (cf. arriba, pp. 93-94), el EIL también (cf. arriba, pp. 94-97). EL ED, finalmente, es susceptible de aparecer en subordinada completiva. Era algo conocido del francés medieval (cf. ejemplos en A. Meiller, 1966) y no es raro escuchar en los medios audiovisuales o leer en la prensa de hoy día ED del tipo siguiente:

Su hijo, también Luis de nombre, explica que «mi padre era presidente de la división de proyectos industriales del Banco...» (revista Tiempo, nº 242, 29-12/4-1 de 1987).

Borbolla afirma en Madrid que «mientras otros se pelean, yo me limito a ejercer de presidente» (El Correo de Andalucía, 2 de junio de 1989, p. 5).

Una última observación, antes de terminar, tocante a las exclusiones que se han operado a menudo de la reproducción indirecta.

La gramática tradicional, que hace derivar el EI del ED, siempre ha puesto de relieve que algunos elementos del ED (exclamaciones, imperativos, etc) se perdían o se transformaban en el curso de las manipulaciones de transposición a EI. A.Banfield, 1973, reafirmó tal posición desde el campo de la lingüística transformacional. Las reacciones suscitadas por su artículo han aportado ejemplos suficientes para probar que el EI puede presentar la mayoría de los elementos que Banfield excluía (cf. McHale, 1978, pp. 254-5; Strauch, 1984, p 160). No insistiremos, pues, en ello.

En cuanto al EIL, las exclusiones han sido menos numerosas, pero no menos tenaces. Nos ocuparemos únicamente del pretérito indefinido, del imperativo y del vocativo.

La exclusión del pretérito indefinido del EIL francés fue el efecto conjugado de los resultados a los que se llegó desde el campo de la gramática y desde el campo de la crítica literaria. Vamos a empezar por el primero de estos enfoques del tema.

Como ya hemos dicho, el EIL ha sido considerado desde Tobler como una variante no conjuncional del EI, debiendo tener, por tanto, el mismo comportamiento que éste en lo relativo a los tiempos verbales y las personas. Los tiempos del EI no serían sino el resultado de una transposición efectuada a partir de la forma del ED según unas reglas 
copiadas, en gran medida, de la concordancia temporum latina, y ello pese al hecho de que los autores no la respetaban sistemáticamente:

Chacun sait aussi qu'en fait le prosateur classique se donne, dans le style indirect, le droit de suivre ou d'abandonner les habitudes de concordance des temps, si foncièrement latines cependant. (J. Bayet, 1930, p. 12).

Lips, por ejemplo, da un cuadro de concordancias (p. 25) según el cual, tras un verbo principal en pasado, el verbo subordinado del EI sólo puede estar también en pasado: imperfecto o pluscuamperfecto, potencial simple o compuesto; el pretérito indefinido no figura. Excluido así del EI, su destierro del EIL parecía natural. Comentando su cuadro de concordancias del EI, Lips escribe: «L'indirect libre use des mêmes procédés, seulement il s'affranchit de toute subordination». Y si desde el principio la escuela de Ginebra excluye el pretérito indefinido del campo del EIL, la escuela de Munich -enfrentada en general con la anterior, pero no en este punto- procederá igual.

Para Lorck, por ejemplo, el defini-Denkakte (pretérito indefinido) incumbe al pensamiento ya constituido y el imparfait-Denkakte (pretérito imperfecto) al pensamiento en curso de constitución; éste está por tanto al servicio de la imaginación; evoca y hace sentir emocionalmente en su desarrollo las escenas referidas; el imperfecto (y el potencial) son por tanto el instrumento ideal del erlebte-Rede (término que se hizo usual en alemán para designar el EIL), del que debe excluirse el pretérito indefinido, forma reservada a la simple constatación de los hèchos.

Bally, 1914, reacciona contra las teorías que asignan valores concretos a los tiempos verbales: es la transposición lo que constituye el EIL y no el empleo de ciertos tiempos:

Le conditionnel n'est pas le temps du style indirect libre: il ne l'est ni plus ni moins que l'imparfait, le présent et le futur, et au fond, n'importe quel temps; ce qui est caractéristique ici, ce n'est pas la présence d'un temps spécial, mais la transposition, et plus encore, la valeur subjective apportée à l'idée verbale. (p. 597).

Bally parece aceptar, pues, «n'importe quel temps» en el EIL, pero de hecho no pone ningún ejemplo de EIL en pretérito indefinido y es lícito suponer que estaba de acuerdo con su discípula Marguerite Lips, que sí defiende explícitamente la incompatibilidad de este tiempo con el EIL; así, para negar el estatus de EIL a un pasaje de Madame Bovary, Lips comenta: «le dernier verbe, mis au passé défini [pretérito indefinido: s'envolèrent], prouve que l'auter a vu tout cela à la place d'Emma, avec son imagination d'artiste» (p. 192).

Al estar de acuerdo las dos escuelas rivales que estudiaron por primera vez el EIL, el «nuevo» DR recién descubierto perdió el derecho de estar en pretérito indefinido y se convirtió, por definición, en el estilo del imperfecto-potencial.

Verschoor, 1959, también se opondrá en este punto a Lips. Para él, el imperfecto y el potencial serán «des indices» de EIL, pero no se negará a aceptar los EIL en pretérito indefinido: 
C'etait, me dit-il, comme si quelqu'un les avait vite remises là-dedans au hasard, quelqu'un qui eûtété surpris dans leur lecture et n'aurait pas eu le temps de les ranger. Il n'eut avec Mme de la Pérouse aucune explication, mais il brûla aussiotôt ses papiers.

\section{Verchoor comenta:}

Soulignons l'emploi du passé défini [pretérito indefinido] dans le style indirect libre (Il n'eut... mais il brûla...); c'est en effet un style indirect libre, car la phrase suivante commence par «Il me parla ensuite de...», ce qui est un indice. Partout ailleurs nous avons trouvé le même phénomène de sorte que les temps (chez l'auteur en question [Gide] ne sont pas un «indice» du style indirect libre. (p. 136).

Pero Verschoor se equivoca según otros autores. Tras citar este pasaje de Gide, M. Hirsch añade:

Ces indices nous permettent sans doute de concevoir que c'est de Monsieur de la Pérouse que le narrateur tient son information. Mais non de percevoir sa parole, ou même son expérience. Certes la nuance est faible entre ces deux lectures... (1980, p. 88).

El matiz es sutil, en efecto; suponemos que el siguiente caso (también citado por Verschoor) Hirsch lo rechazará igualmente según el mismo razonamiento. A nuestro parecer, sin embargo, este ejemplo contiene la reproducción clara del discurso de Alexandre, es decir, contiene DR; ¿de qué tipo si no es EIL?:

Je suis avec Ghéon. Alexandre nous aborde en disant: -Je viens de perdre ma femme (...). Nous nous querellions trop, continue-t-il; et il raconte que, la veille du premier jour de l'an, comme il s'était montré plus brutal encore que de coutume, la pauvre fille, exaspérée, s'était sauvée chez une amie. Celle-ci, morphinomane, lui conseilla de se "piquer». Aline calcula-t-elle mal la dose? ou voulut-elle la forcer?... Elle en prit tant qu' une heure après elle était morte. (Gide, Journal; Verschoor, p. 138).

Si el imperfecto y el potencial pueden constituir un indicio de EIL para Verschoor, es porque la mayoría de los EIL contenidos en la novela realista del XIX presentan efectivamente estos tiempos. No se olvide que el primer comentario sobre el EIL lo hizo Tobler a partir de un pasaje de Zola; que Proust redescubre el «estilo» en Flaubert, a pesar de no haber oído hablar del EIL; que M. Lips et G. Lerch pondrán de acuerdo la escuela saussureana suiza y la escuela vossleriana alemana para admitir que el «verdadero» EIL aparece por primera vez -salvo raros precedentes- en la novela realista francesa del XIX. La crítica literaria comenzará así sus análisis del EIL a partir de textos donde éste está basado, en efecto, en el imperfecto-potencial. De ahí la creación de un modelo canónico al que deberán adaptarse las realizaciones del estilo; aquéllas que no lo hacen simplemente no son reconocidas como tales o son tachadas de «marginales»: caso de Gide citado, caso del EIL de la lengua oral, caso del EIL de otros períodos 
literarios y caso, incluso, de los EIL que, presentes en los autores a partir de cuyas obras se ha creado el canon, no siguen éste al pie de la letra:

Dans ces récits au passé qui sont les romans de Flaubert, je n'ai pas trouvé de forme nette d'indirect libre au présent. (C. Gothot-Mersch, 1983).

En Flaubert, sin embargo, M.-T. Jacquet, 1980, ha encontrado un gran número de ejemplos de EIL en presente (por tanto, no «verdaderos»), aunque ella les niegue el nombre mismo de EIL. Este es el comentario de Genette al respecto:

La concordance des temps, toutefois, n'est probablement pas una règle absolue, si tant est qu'il en existe une seule dans un type aussi ouvert à l'initiative stylistique [Genette está hablando del EIL]. L'expression d'une opinion relevant, ou croyant relever d'un savoir ou d'une vérité intemporelle, peut entraîner un passage au présent gnomique, ou épistémique [Siguen varios ejemplos sacados de Bouvard et Pécuchet]. MarieThérèse Jacquet, à qui j'emprunte ces exemples, a bien mis en relief l'importance de cette forme dans Bouvard. Mais son terme de «style direct intégré» me semble tirer abusivement vers le style direct cette forme intermédiaire que je préférerais maintenir dans la sphère du discours indirect libre, par un terme tel que «discours indirect libre sans concordance des temps». (1983, p. 36; itálicas nuestras).

Que nosotros sepamos, el que a veces los adverbios de tiempo no estén referenciados a la situación enunciativa del locutor que refiere ${ }^{15}$ nunca ha inspirado a nadie un término como «style indirect libre sans accord des adverbes». Y no es que en principio estemos contra la idea de hacer subgrupos dentro de los diferentes tipos de DR; lo que no podemos aprobar es que esta subdivisión esté basada en rasgos «anormales» en relación a lo que sería un tipo «normal», en rasgos que, sin sacar los subgrupos en cuestión de la «esfera» de uno de los tres modos de DR, harían de ellos una especie de rareza discurisva. Todavía más condenamos, por tanto, la posición de M.-T. Jacquet, es decir, todo intento de sacar el EIL en presente de verdad epistemológica de la esfera misma del EIL para convertirlo en una especie de DD.

Insistimos en que todo a priori sobre la naturaleza de los diversos modos de DR, basado en lo que es su empleo en ciertos escritores o en cierta época, sólo puede llevar a ignorar las verdaderas posibilidades de esos modos e incluso a no reconocerlos aunque estén explícitamente señalizados:

Je signalerai encore, en passant, deux autres procédés apparentés à l'italique et aux guillemets: le procédé typographique qui consiste à intercaler dans une phrase un «dit-il» ou un «disait-il». «Mais il ne fallait point, dit le banquier, qu'il fût dépendant de personne» (...). La formule joue, dans ce cas-ci le rôle d'indicateur de style indirect

15 «Toute la treme narrative [la de Berlin Alexanderplatz], de type "histoire", repose sur l'emploi de la toisième personne et tantôt du prétérit, tantôt du présent (à valeur aoristique). Notons qu'aussi bien le prétérit que le présent sont construits avec les deux séries d'adverbes (la série «aujoud'hui» et la série «ce jour-là»). (J. Simonin, 1984, p. 32). 
libre. Pratique courante, par exemple chez Balzac, qui l'emploie volontiers quant à lui dans des phrases narratives: «Mais elle se contenta, disait-elle en riant, de sa propre admiration». (C. Gothot-Mersch, 1983, p. 216; itálicas nuestras).

Nos parece que, en el último ejemplo que la autora cita, el inciso indica, como en el anterior de Flaubert, la presencia de un EIL. Como se ve, la única diferencia entre ambos es el tiempo verbal utilizado; es el pretérito indefinido empleado por Balzac lo que provoca que Gothot-Mersch no lo haya reconocido: este EIL no se adapta al tipo canónico en imperfecto y/o potencial.

Esta claro que si los primeros estudios sobre EIL se hubieran hecho sobre la obra de Gide -donde, recordémoslo, el imperfecto no es un «indicio», según Verschoor-, o sobre la de La Bruyère -donde abundan los EIL en presente- o sobre la literatura medieval francesa -donde los EIL en presente-futuro son frecuentes y cumplen una función específica-, o sobre Döblin ${ }^{16}$, el EIL canónico hubiera sido bastante diferente.

La persistencia de la opinión de que el pretérito indefinido no puede aparecer en EIL se debe también, y en gran medida, a que su aceptación daría al traste con buena parte del marco teórico desde el cual se enfoca su estudio. Si M. Hirsch, por ejemplo, tiene que rechazar los casos encontrados por Verschoor, es porque el empleo del pretérito en el EIL no responde a los presupuestos guillaumianos de los que ella parte. Si Banfield hace lo mismo, es porque el aoristo sólo puede aparecer en contextos dominados por el símbolo S, pero nunca cuando lo están por E: «Thus, this tense does not occur in the style indirect libre, which consists of expressions (E)» (1973, p. 36).

L. Danon-Boileau afirma: «Ce que nous voulons simplement indiquer c'est que les 'types de discours', tels qu'ils sont définis, proposent comme incompatibles des combinaisons que les exemples attestent» (1982, p. 84). Esto es exactamente el fundamento de nuestra argumentación; pero he aquí la posición de Danon-Boileau en cuanto al EIL:

Considérons l'exemple suivant: «L'inspecteur tira sur sa pipe; Paul vint-il ce soir-là retrouver son amie?»- On peut se demander si la seconde phrase est du type S. I. L. A priori [subrayamos nosotros], le passé simple semble toutefois exclure cette interprétation. En revanche, si l'on avait: «Paul était-il venu ce soir-là retrouver son amie?» il pourrait s'agir d'une question de l'inspecteur. (1982, p. 177).

Ya se ve que Danon-Boileau, a pesar de su oposición a las definiciones restrictivas de los tipos de DR, acepta aquí un a priori que los hechos desmienten. Si lo hace es simplemente para salvaguardar el conjunto de su marco teórico (que es también el de Bouscaren):

Pour qu'un énoncé soit un énoncé de style indirect libre, il faut: - que ce soit un commentaire

\footnotetext{
${ }^{16} \mathrm{He}$ aquí el comentario de Simonin sobre el empleo de los tiempos en los EIL de Berlin Alexanderplatz: «Le temps, contrairement à la personne, n'est pas un critère net d'identification du DIL -dans un contexte au prétérit, le DIL peut être au prétérit ou au présent, ou passer de l'un à l'autre» (1984, p. 44).
} 
- que l'antécédeñt de ce commentaire dans la relation de dépendance soit un énoncé rapporté. (1984, p. 67).

Ahora bien, el «commentaire» es incompatible con el empleo del pretérito indefinido:

Les procès d'un commentaire ne déterminent pas un événement pourvu d'une référence temporelle de type «instant ponctuel». Cette absence de référence temporelle découle du fait que le procès du commentaire est affecté d'un aspect nonaoristique... (1984, p. 62).

Nótese que, de cualquier manera, el ejemplo del inspector propuesto por el autor no constituye para él un EIL incluso si se sustituye el pretérito por el pluscuamperfecto. La segunda de sus condiciones no se cumple, en efecto: el «antécédent», «l'inspecteur tira sur sa pipe», no es un DR; así pues, el soporte de la modalidad interrogativa no puede ser (según la teoría de Danon-Boileau) más que el enunciador primario. Pero, por el sentido, el mismo Danon-Boileau sostiene que hay que admitir que la pregunta se le plantea al inspector, no al narrador anónimo que nos refiere sus pensamientos; hay por tanto contradicción, e incluso doble contradicción, ya que el segundo enunciado presenta una modalidad interrogativa cuyo soporte «semble être le narrateur rapporté ce qui est un indice du caractère rapporté de l'ensemble de l'énoncé-, tandis que le passé simple interdit que l'on ait affaire a un SIL» (itálicas nuestras). Ante tales contradicciones, la solución de Danon-Boileau es considerar el segundo enunciado -al igual que otros citados anteriormente-como un «énoncé primaire mimétique, soulignant para là, qu'à la différence du SIL, on n'assistait pas à l'avènement d'un niveau d'énoncé rapporté».

Repetimos que una teoría, para ser válida, debe dar cuenta de los hechos reales, y no lo contrario: no son los hechos los que deben adaptarse a postulados teóricos previos. A menudo tenemos la impresión de que es esta segunda opción la elegida por algunos investigadores.

Que el EIL no es incompatible con el pretérito indefinido es para nosotros incontestable. Que, en francés, haya menos casos de EIL en pretérito que de EIL en imperfecto no nos sorprende, en cambio. Otra cosa sería de extrañar, dado que el francés hablado ha eliminado el pretérito indefinido de su sistema verbal. Las posibilidades de encontrar un EIL en pretérito indefinido en lengua oral son pues prácticamente nulas; $y$, en el EIL de la lengua escrita, el pretérito no puede ser tampoco tan corriente como el impertecto, el pluscuamperfecto o el pretérito perfecto: es discurso -en el sentido amplio- lo que se reproduce; salvo en los casos -que no creemos, siendo generosos, que lleguen a un máximo de la mitad del total- en que el narrador usa sus propias palabras y su propio registro de lengua, el EIL de la lengua escrita, sobre todo el literario, aspira a reflejar la lengua del personaje, con lo que el pretérito se ve relegado a la inoperancia por la misma razón que en los EIL orales.

M. Cohen se pregunta a propósito de la proliferación de imperfectos en la literatura francesa del siglo XIX: «cette attitude n'est-elle pas le reflet d'une gêne à écrire une 
forme qui ne se parle pas?» (1954,p. 106). Tal subreabundancia con respecto a los siglos anteriores se da únicamente en la reproducción del discurso de los personajes; nuestra respuesta a su pregunta sólo puede ser, por tanto, afirmativa. Se puede alegar incluso, en favor de esta explicación, que en otras lenguas románicas, donde el pretérito indefinido sigue vivo en lengua hablada, el uso de este tiempo en los EIL ha sido reconocido desde los primeros estudios sobre el tema. G. Herczeg (1963, p. 60) lo reconoce así pará el italiano a pesar de sus esfuerzos por no ir en contra de la teoría que pide que el EIL esté siempre en imperfecto-potencial. G. Verdín Díaz, que trata igualmente de no atentar contra los tópicos sobre el EIL, tiene que reconocer lo mismo en lo relativo al español (1970, p. 84). En francés, de hecho, ha sido siempre usual recurrir al pretérito cada vez que, en un EIL con el que se está refiriendo el discurso de un personaje, éste pasa a reproducir las palabras de otro personaje:

[El príncipe Mainau le ha contado a Alexis la vida de los suegros de éste, quien escribe la siguiente carta a su mujer:] C'était vraiment un récit de voyage, puisque le prince avait connu votre père au cours d'une expédition, déjà lointaine, dans les Antilles françaises. Le docteur Thiébaut fut un explorateur célèbre, il s'était marién'étant déjà plus jeune; vous étiez née là-bas (...). Vous aviez grandi dans un milieu sévère, et pourtant très aimant; vous avez eu l'enfance d'une petite fille heureuse. Certe, mom amie, il n'est pas nécessaire que je vous raconte votre histoire. (M. Yourcenar, Alexis, Gallimard, pp. 93-94)

Je vis Pradelle. Il me raconte ce qu'il savait. Le surlendemain de ma recontre avec Zaza, Mme Pradelle était seule dans son appartement quand on sonna; elle ouvrit et elle se trouva devant une jeune fille bien vêtue... (S. de Beauvoir, Mémoires d'une jeune fille bien rangée, Gallimard, p. 10).

Si la mayoría de los estudiosos del EIL han sido contrarios al pretérito indefinido, al menos ha habido discusión y explicación de razones al respecto. Por el contrario, cabe extrañarse del acuerdo unánime existente en que el imperativo y el vocativo no pueden aparecer en EIL. Esto, naturalmente, tiene sus causas.

El imperativo, junto con el vocativo y los pronombres de primera y segunda persona, muestran claramente la presencia de un locutor y de un alocutario. No por casualidad Banfield llama «addressee-oriented adverbials» a los adverbios de frase del tipo «sinceramente», que forman parte de la misma serie. Está claro que, si se empieza negando, como lo hace Banfield, que el EIL tenga locutor, la supresión del alocutario viene por sí sola y todos estos elementos se hacen incompatibles con el EIL. Pero, incluso cuando se admite que el EIL tiene locutor, si se parte del modelo de la novela tradicional, se encontrará por fuerza un narrador que refiere los discursos de los personajes, los cuales no coinciden con el narratario; esto hace que el narrador no emplee nunca la segunda persona, ni en EIL ni en EI; sólo la tercera persona aparece en ellos $\mathrm{y}$, como no se dispone de forma imperativa de tercera persona, se concluye de manera abusiva que el imperativo es incompatible con el EIL: en éste, todo imperativo del discurso «original» estará reproducido por medio del subjuntivo o de un verbo modal. 
Ahora bien, basta con invertir el esquema para conseguir imperativos en EIL. Que Carlos me hable de Bernardo empleando una forma exhortativa de subjuntivo, que yo le refiera este discurso a Bernardo y el imperativo aparecerá:

Carlos a mí: Bernardo no está malo; piensa demasiado, eso es todo. Que trabaje, verá cómo se le pasa la depresión.

Yo a Bernardo: Carlos me ha dicho que en realidad no estás malo; simplemente piensas demasiado. Trabaja y se te pasará todo.

No hemos encontrado ningún autor que defienda que existen EIL en imperativo. McHale y Strauch, firmemente opuestos a las exclusiones efectuadas por Bañfield (tanto del EIL como del EI), no ponen ningún ejemplo de EIL que contenga un imperativo. Bally creía que el imperativo es posible en EIL sólo cuando adopta una forma exclamativa del tipo «songez donc!» ${ }^{17}$.

Existe el mismo acuerdo unánime en considerar el vocativo como incompatible con el EIL, pese a que Bally citaba ya el pasaje siguiente, también discutido por Kalepky y Lorck:

Resté seul dans l'embrasure, le cardinal s'y tint immobile, un instant encore... Et ses bras frémissants se tendirent en un geste d'imploration: $O$ Dieu! puisque la science des hommes était si courte, puisque ce médecin s'en allait ainsi, heureux de sauver l'embarras de son impuissance, $\hat{o}$ Dieu! que ne faisiez-vous un miracle pour montrer l'éclat de votre pouvoir sans borne! (...). (E. Zola, Rome; Bally, 1914, p. 415).

Sólo hemos encontrado un autor que admita la posibilidad del vocativo en EIL: M. Plénat, quien, precisamente a propósito de este pasaje, comenta: «Si l'allocutaire du cardinal (Dieu) est présent dans le discours rapporté au S.I.L., c'est qu'il est aussi, et d'abord, l'allocutaire de Zola" (1979, p. 107). En otros autores el anatema contra el vocativo es general.

E incluso Plénat introduce un «d'abord» que, a nuestro juicio, está de más. Para nosotros la cuestión se reduce a lo siguiente: cada vez que el alocutario del locutor del discurso original, real o supuesto, coincide con el alocutario del locutor que refiere, el apóstrofe es posible en EIL. Esto no ocurre normalmente en los textos literarios de perfil clásico. De ahí la creencia de que el EIL es incompatible con el vocativo. En lengua hablada, tal coincidencia es más probable:

Alice se fâcha et me dit: Partez immédiatement, \{Paul/mon ami\}

Alice se fâcha: je devais partir immédiatement, \{Paul/mon ami/*son ami $\}$

Según Plénat, en el segundo caso, Paul y mon ami representan al alocutario de Paul locutor reproductor y no forman parte del EIL. Estamos de acuerdo; en el segundo caso, el alocutario de Paul -otra persona también llamada Paul- no coincide con el

${ }^{17}$ Ver también el pasaje de A. Daudet que Bally cita en 1912, p. 599 («Et maintenant rattrape-les!»), sin hacer la más mínima referencia a ello. 
alocutario -Paul, el locutor reproductor- del locutor del discurso original -Alice. Pero se puede imaginar que esto ocurra y aparecerá el vocativo en EIL:

Mais si! rapelle-toi qu'elle s'est fâchée: Tu devais, \{Paul/mon ami/grand imbécile\}, partir immédiatement.

He aquí, en el terreno literario, un ejemplo citado por Batjin, quien lo considera un «discurso por sustitución»; para nosotros éste es sólo una variante del EIL en que el narrador reproduce el discurso del personaje con su propio registro de lengua:

Là-bas s'alignent les sommets identiques des collines; entre elles, un chemin isolé se perd au loin, sinistre. La jeune poitrine du prisonnier était agitée de lourdes pensées. (...) Le chemin lointain mène en Russie, dans le pays où il a entamé fièrement et sans souci sa belle jeunesse; où il a connu ses premières joies, où il a aimé tant de beauté, où il a étreint une souffrance sévère, où il a détruit toute espérance, toute joie et tout désir par sa vie agitée. (...) Il a appris à connaître les joies et le monde et a connu le prix d'une vie incertaine. Dans les coeurs des hommes, il a trouvé la trahison, dans les aspirations à l'amour, un songe insensé. (...) Liberté, il ne cherchait que toi dans le monde sublunaire. (...) Tout est joué (...) il ne voit rien au monde qui puisse lui apporter l'espérance. Et vous, dernières rêveries, vous aussi lui échappez. Il est esclave. (Pushkin, El prisionero del Cáucaso; Bajtin, 1977, p. 192).

En las letras hispanoamericanas contemporáneas se pueden encontrar empleos del vocativo en EIL incluso cuando no hay coincidencia de alocutario entre locutor reproductor y locutor del discurso original.

El moscardón bate las alistas azules, despega con suave impulso de la frente rosada de la madre Patrocinio, se pierde trazando círculos en la luz blanca y el práctico iba a apagar el motor, Sargento, ya estaban llegando, detrás de esa quebradita venía Chicais. Pero al Sargento el corazón... (M. Vargas Llosa, La casa verde).

\section{Trabajos citados}

AUTHIIER Jacqueline, «Les formes du discours rapporté. Remarques syntaxiques et sémantiques à partir des traitements proposés», DRLAV, 17, 1978, 1-87.

AUTHIER Jacqueline y MEUNIER André, «Exercices de grammaire et discours rapporté», Langue française, 33, 1977, 41-67.

BAKHTINE Mikhail, Le marxisme et la philosophie du langage, París, Minuit, 1977.

BALLY Charles, «Le style indirect libre en français moderne», Germanisch-Romanisch Monatsschrift, IV, 1912, 549-556 y 597-606.

«Figures de pensée et formes linguistiques», G. R. M., 1914, 405-422 y 456-470. 
BANFIELD Ann, «Narrative style and the grammar of direct and indirect speech», Foundations of Language, 10, 1973, 1-39.

BAYET Jean, «Le style indirect libre en latin», Revue de Philologie, 1930, 5-23 y 327 342.

BRUÑA CUEVAS Manuel, «Le style indirect libre chez Marie de France», Revue de Linguistique Romane, 52, 1988, 421-446.

«Sobre la mímesis del discurso», Primer Seminario de Narrativa, julio de 1989, Cádiz. (En prensa).

CERQUIGLINI Bernard, La parole médiévale, París, Minuit, 1981.

COHEN Marcel, Grammaire et style, 1450-1950, París, Editions Sociales, 1954.

COHEN Dorrit, Transparent Minds. Narrative Modes for Presenting Consciousness in Fiction, Princeton U. P., 1978; según la traducción francesa La transparence intérieure. Modes de représentation de la vie psychique dans le roman, París, Seuil, 1981.

DANON-BOILEAU Laurent, Produire le fictif, Paris, Klincksieck, 1982.

DANON-BOILEAU Laurent y BOUSCAREN Janine, «Pour en finir avec Procuste», Langages, 73, 1984, 57-73.

DUCROT Oswald, Les mots du discours, París, Minuit, 1980.

GENETTE Gérard, Figures III, París, Seuil, 1972.

Nouveau discours du récit, París, Seuil, 1983.

GOTHOT-MERSCH Claudine, «La parole des personnages», Travail de Flaubert, París, Seuil, 1983, 199-238.

GRESILLON Almuth, «Un cas de discours rapporté: reproduction, transformation, déformation du discours biblique dans le discours politique de Heine» DRLAV, 17, 1978, 123-150.

HERCZEG Giulio, Lo stile indiretto libero in italiano, Florencia, Sansoni-Editore, 1963.

HERNADI Paul, «Free Indirect Discourse and Related Techniques», apéndice en Beyond Genre: New Directions in Literary Classification, Londres, Comell U.P., 1972, 187-205.

HIRSCH Michèle, «Le style indirect libre: linguistique ou histoire littéraire?», La psychomécanique et les théories de l'énonciation, P. U. de Lille, 1980, 79-89.

JACQUET Marie-Thérèse, «La fausse libération du dialogue ou le 'style direct intégré, dans Bouvard et Pécuchet», Annali della Facoltà di Lingue e Letterature Straniere dell'Università di Bari, 1, 1980.

LERCH Gertraud, «Die uneigentlich direkte Rede», Idealistische Neuphilologie, Festschrift für Karl Vossler, Heidelberg, 1922, 107-119.

LIPS Marguerite, Le style indirect libre, París, Payot, 1.926.

LORCK Etienne, «Passé défini, Imparfait, Passé indéfini», Germanisch-Romanisch Monatsschrift, 1914, 43-57, 100-113 y 177-191.

Die «erlebte Rede». Eine sprachliche Untersuchung, Heidelberg, 1921.

McHALE Brian «Free indirect discourse: a survey of recent accounts», PTL, 3, 1978, 249-287.

«Unspeakable sentences, unnatural acts», Poetics Today, 4, 1984, 17-45. 
MEILLER Albert, «Le problème du 'style direct introduit par que' en ancien français», Revue de Linguistique Romane, 30, 1966, 353-373.

MILNER Jean-Claude, De la syntaxe à l'interprétation, París, Seuil, 1978.

PLENAT Marc, «Sur la grammaire du style indirect libre», Cahiers de grammaire, 1, 1979, 95-140.

REY-DEBOVE Josette, «Notes sur une interprétation autonymique de la littérarité: le mode du 'comme je dis'», Littérature, 4, 1971, 90-95.

REYES Graciela, Polifonía textual, Madrid, Gredos, 1984.

SIMONIN Jenny, «Les plans d'énonciation dans Berlin Alexanderplatz de Döblin, ou de la polyphonie textuelle», Langages, 73, 1984, 30-56.

STERNBERG Meir, «Proteus in Quotation-Land. Mimesis and the Forms of Reported Discourse», Poetics Today, 3:2, 1982, 107-156.

STRAUCH Gérard, «De quelques interprétation récentes du style indirect libre», RANAM, VII, 1974, 40-73. «De la 'littéralité, du discours rapporté», RANAM, XVII, 1984, 159-182.

TOBLER Adolf, «Vermischte Beiträge sur französischen Grammatik», Zeitschrift für romanische Philologie, 11, 1887, 433-441.

VERDIN DIAZ Guillermo, «Introducción al estilo indirecto libre en español», Revista de Filología Española, anejo XCI, 1970.

VERSCHOOR Jan Adriaan, Estude de grammaire historique et de style sur le style direct et les styles indirects en français, Groningen, V. R. B., 1959.

WAGNER Robert-Léon, «C. r. de J. A. Verschoor, Etude de grammaire historique et de style...» Le français moderne, XXVIII, 1960, 222-224. 